\title{
Replacement of the dissected thoracoabdominal aorta: Some like it cold
}

\author{
Jean Bachet, MD, FEBCTS
}

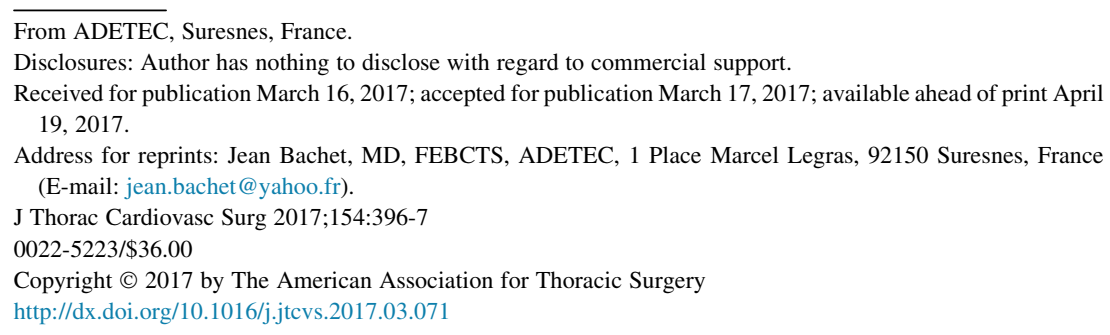

The experience of replacement of chronically dissected thoracic and thoracoabdominal aorta with deep hypothermic circulatory arrest reported in this issue of the Journal by Corvera and colleagues ${ }^{1}$ is probably the largest published so far. Corvera and colleagues ${ }^{1}$ have obtained outstanding results not only in terms of in-hospital and late mortalities but also in terms of postoperative morbidity.

Apparently, the first attempt to use profound hypothermic circulatory arrest during surgery of the thoracoabdominal aorta was made by Guilmet and colleagues ${ }^{2}$ in Paris as early as 1981. Four patients underwent operation. There was no postoperative mortality and no spinal cord injury. Unfortunately, this experience was published in a local French medical journal and was mostly ignored by the international surgical community. In 1995, Kouchoukos and coworkers ${ }^{3}$ published a large cohort of 51 patients in which the technique had been used with satisfactory results. After this publication, the technique became well known and accepted. It is strange, however, that the technique did not attain wide popularity and that it has not been largely adopted worldwide.

This lack of popularity is most probably because the use of profound hypothermia is associated with a long and tedious duration of cardiopulmonary bypass (almost 5 hours in the study of Corvera and colleagues ${ }^{1}$ !), with such sufficiently frequent and somewhat important complications and drawbacks as coagulation and inflammatory disorders, acute renal failure, and pulmonary lesions and dysfunction. ${ }^{4}$ Apparently, such an association was not the case in the experience reported by Corvera and colleagues, ${ }^{1}$ and they are certainly to be congratulated for the excellence of the intraoperative and postoperative management of their patients. Yet, one swallow does not a summer make, and several studies have demonstrated that such good results are not always obtained. $^{5,6}$

The strategy of using profound hypothermic circulatory arrest is logical and even mandatory when the location of the lesions or their development preclude the placement

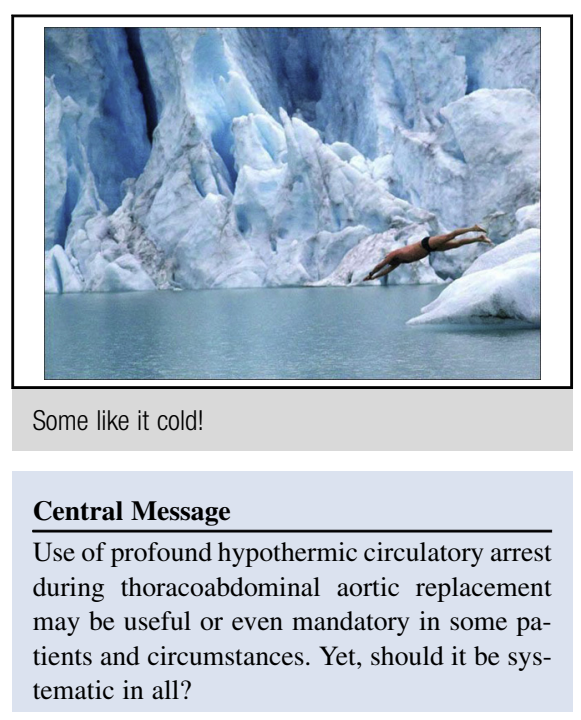

See Article page 389

of clamps on the proximal aorta, or when the aortic arch is involved and needs to be replaced simultaneously.

But for the rest?

One may, indeed, observe that in about one-third of the patients the aortic replacement concerned only the descending aorta. It is largely demonstrated that in such cases the risk of spinal cord injury is quite low when the procedures are performed at mild hypothermia with the aid of cardiopulmonary bypass and distal perfusion. Moreover, recent reports including very large cohorts of patients ${ }^{7}$ have indeed demonstrated that thoracoabdominal replacements with left heart bypass or conventional cardiopulmonary bypass, at moderate hypothermia and with such adjuncts as cerebrospinal fluid drainage, sequential crossclamping, distal perfusion, and so on, have resulted in outcomes as satisfactory as those reported in the study of Corvera and colleagues. ${ }^{1}$ And this is also the case for the procedures performed according to the collateral network concept, with initial occlusion and division of the critical intercostal arteries under the assessment of somatosensory or motor evoked potentials. ${ }^{8,9}$

In this regard it is noteworthy that Corvera and colleagues, ${ }^{1}$ who state that their use of profound hypothermic circulatory arrest allows them to avoid other adjuncts, decided starting in 2013 to place cerebrospinal fluid drainage in all patients with Crawford extents II and III because of "the increased number of paraplegia and 
paraparesis in patients with extensive repairs or completion of thoraco-abdominal replacement after prior aortic repair." Weren't the patients' spinal cords already protected by the profound hypothermia?

So, the main question concerns the systematic use of profound hypothermia in all patients who require thoracic and thoracoabdominal aortic replacements. Considering the drawbacks of this method, one might wonder whether its obvious benefit in some patients with very severe or extended lesions might not be counterbalanced by the possible complications it implies and whether a simpler mode of perfusion is better fit in many anatomic conditions and pathologic circumstances. Only a large randomized, controlled study could provide the surgical community with a proper answer. But, of course, such a study is totally unrealistic!

\section{References}

1. Corvera J, Copeland H, Blitzer D, Hicks A, Manghelli J, Hess P, et al. Open repair of chronic thoracic and thoracoabdominal aortic dissection using deep hypothermia and circulatory arrest. J Thorac Cardiovasc Surg. 2017;154: 389-95.
2. Guilmet D, Rosier J, Richard T, Bachet J, Goudot B, Bical O. Chirurgie des anévrysmes thoraciques et thoraco-abdominaux intéressant l'artère d'Adamkiewicz: intérêt de l'hypothermie profonde (French). Nouv Presse Med. 1981;10:3303-6

3. Kouchoukos NT, Daily BB, Rokkas CK, Murphy SF, Bauer S, Abboud N. Hypothermic bypass and circulatory arrest for operations on the descending thoracic aorta and thoracoabdominal aorta. Ann Thorac Surg. 1995;60:67-76; discussion 76-7.

4. Kieffer E, Koskas F, Walden R, Godet G, Le Blevec D, Bahnini A, et al. Hypothermic circulatory arrest for thoracic aneurysmectomy through left-sided thoracotomy. J Vasc Surg. 1994;19:457-63.

5. Safi HJ, Miller CC III, Subramaniam MH, Campbell MP, Iliopoulos DC, O'Donnell JJ, et al. Thoracic and thoracoabdominal aortic aneurysm repair using cardiopulmonary bypass, profound hypothermia, and circulatory arrest via left side of the chest incision. J Vasc Surg. 1998;28:591-8.

6. Coselli JS, Bozinovski J, Cheung C. Hypothermic circulatory arrest: safety and efficacy in the operative treatment of descending thoracic and thoracoabdominal aortic aneurysms. Ann Thorac Surg. 2008;85:956-63; discussion 964.

7. Coselli JS, LeMaire SA, Preventza O, de la Cruz KI, Cooley DA, Price MD, et al. Outcomes of 3309 thoracoabdominal aortic aneurysm repairs. J Thorac Cardiovasc Surg. 2016;151:1323-37.

8. Griepp RB, Ergin MA, Galla JD, Lansman S, Khan N, Quintana C, et al. Looking for the artery of Adamkiewicz: a quest to minimize paraplegia after operations for aneurysms of the descending thoracic and thoracoabdominal aorta. J Thorac Cardiovasc Surg. 1996;112:1202-13; discussion 1213-5.

9. Etz CD, Kari FA, Mueller CS, Silovitz D, Brenner RM, Lin HM, et al. The collateral network concept: a reassessment of the anatomy of spinal cord perfusion. $J$ Thorac Cardiovasc Surg. 2011;141:1020-8. 